\title{
Study on the stability and antioxidant effect of the Allium ursinum watery extract
}

\author{
Salomeia Putnoky', Angela Caunii ${ }^{2}$ and Monica Butnariu ${ }^{3^{*}}$
}

\begin{abstract}
Background: Organosulfur compounds usually present a reduced stability especially in the presence of oxygen. This research aimed to study the stability and antioxidant potential of the Allium ursinum watery extract.

Results: The decrease of the antioxidant capacity verifies an exponential relation which may be formally associated to a kinetically pseudomonomolecular process. The exponential regression equation allows the half-life of the degradation process to be determined, this being 14 hours and 49 minutes in a watery environment at room temperature.

Conclusions: The watery extract of Allium ursinum changes its proprieties in time. This might be explained by the network of hydrogen bonds in a watery environment which has a protective effect on the dissolved allicin molecule.
\end{abstract}

\section{Background}

The species belonging to the Allium family have been used for a long time as a remedy for the prevention and treatment of certain diseases [1]. The adjectives associated to these plants i.e. spicy, imposing, distinct and even the latin name Allium, deriving from the Celtic "all" meaning pungent, reflects the presence of certain flavours and scents, all sharing a single element: sulfur. Many of these sulfur compounds contain the allyl group, name deriving from Allium. The very presence of these organosulfur compounds defines the character of this species. The wide spectrum of therapeutic actions has been attributed to organosulfur substances [2,3]. The chemistry of Alliaceae offers examples of organosulfur compounds with an amazing physiological activity, organosulfur intermediate compounds with unusual bonds $[4,5]$, challenging analytical problems, stereochemical characteristics related to the presence of sulfur, unusual organosulfur heterocycles with important spectroscopic properties, redox reactions involving sulfurs, pericyclic reactions in organo-synthetical chemistry [6,7]. The first exhaustive synthesis on these compounds was published

\footnotetext{
* Correspondence: monicabutnariu@yahoo.com

${ }^{3}$ Chemistry and Vegetal Biochemistry, Banat's University of Agricultural Sciences and Veterinary Medicine from Timisoara, Calea Aradului no. 119, 300645, Timisoara, Romania

Full list of author information is available at the end of the article
}

in 1992 [8]. This paper, besides presenting an impressive number of chemically characterised compounds, confirms previous data according to which the main component with a therapeutic action is allicin $[9,10]$. A. ursinum (ramson) and other representatives of the Allium species, contain $1-5 \%$ nonprotein secondary metabolites of aminosulfuric acids [11]. In the cell, the stable precursor of the antibacterial principle of Cavallito, the S-oxyde (+/-) of S-2propenyl cysteine and the S-oxyde of S-alkenyl cysteine (odour and flavour precursors) are located in the cytoplasm while the enzyme alliinase in the vacuole [12]. Both in the paper by Block [13] as well as in previous published works, two beneficial properties of this component are highlighted: the antibacterial effect and the antioxidant capacity (the property to bind reactive free radicals) $[14,15]$. Using chromatographic assays, the active components were isolated and subsequently identified. Analyses by high-performance liquid chromatography suggested that these compounds were sulfur components, with a characteristic absorbance at $250 \mathrm{~nm}$. Gas chromatography-mass spectrometry analyses allowed the chemical structures of the isolated components to be investigated $[3,16]$. Ramson, garlic and onion extracts have been used in popular medicine, and commercial products of these plants record an increasing use.

According to epidemiologic evidence, low cancer risks are associated to a high intake of alliaceae $[17,18]$, reason
(C) Chemistry Central

(c) 2013 Putnoky et al.; licensee Chemistry Central Ltd. This is an Open Access article distributed under the terms of the Creative Commons Attribution License (http://creativecommons.org/licenses/by/2.0), which permits unrestricted use, distribution, and reproduction in any medium, provided the original work is properly cited. 
for which health organizations recommend the use of $A$. ursinum as raw material in diets aiming to prevent cellular malignancy. For all these reasons, a detailed research of the organosulfur chemistry of the genus Allium seems justified $[19,20]$. Literature data states that in a watery solution, allicin presents an increased stability as compared to other solvents (e.g. alcohol, acetone etc.) [21].

The purpose of the present study is the watery extract of $A$. ursinum. This research intends to study the stability of the allicin containing watery extract of $A$. ursinum.

The degradation in time of this compound affects the stability and the period of use of ramson preparations, and as such, a significant study of this degradation process is not without interest.

\section{Results}

\section{The spectrophotometric study of the extract}

The UV absorption spectrum of the A. ursinum solution, obtained against distilled water in a $1 \mathrm{~cm}$ quartz cuvette, is presented in Figure 1. The profile of the absorption spectrum is significant in assessing the areas of highest and lowest absorption, and distinct profiles can signify the effects of different molecules. Using the literature value of the specific absorption at $240 \mathrm{~nm}(145.4 \mathrm{dL} / \mathrm{g} \cdot \mathrm{cm})$, the allicin content reported to fresh raw material was determined: $0.694 \mu \mathrm{g} / \mathrm{ml}$.

\section{Determination and characterization of the antioxidant capacity}

Figure 2 shows spectrum change of the watery extract of A. ursinum in time, with the generation sequence of reactive oxygen species (singlet oxygen and superoxide anion radical). The evolution of the emitted light intensity (expressed as detector signal) is recorded on a curve shaped as shown in Figure 3. The curves a-e in Figure 3

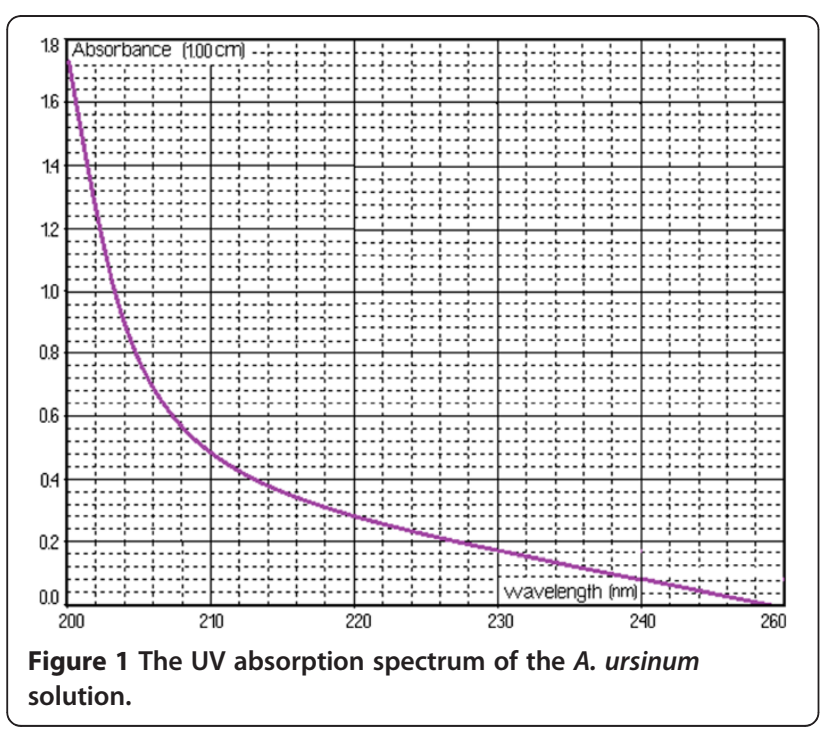

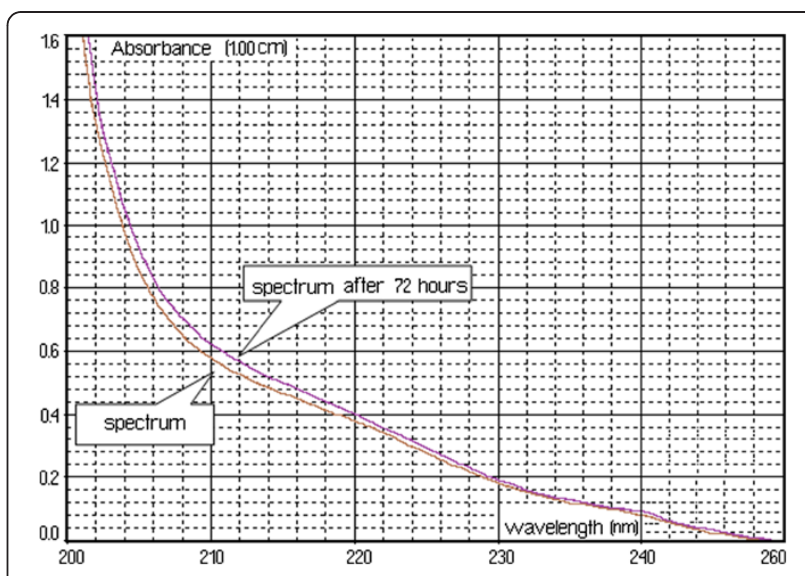

Figure 2 Spectrum change of the watery extract of $A$. ursinum in time.

corresponds to increasing quantities of antioxidant in the system. It may be observed that, with the increase in the amount of antioxidant, the ascendant branch of the curves is preceded by increasing induction intervals. Figure 4 presents a group of curves $(\mathrm{a}-\mathrm{d})$ obtained with the help of a series of standard solutions. The values of induction times (IT) and effective induction times (EIT) as well as the conventional expression of the antioxidant character (vitamin $\mathrm{C}$ nmol equivalents) are presented in Table 1. The antioxidant character of the analysed products is obtained by comparing the curves associated to these

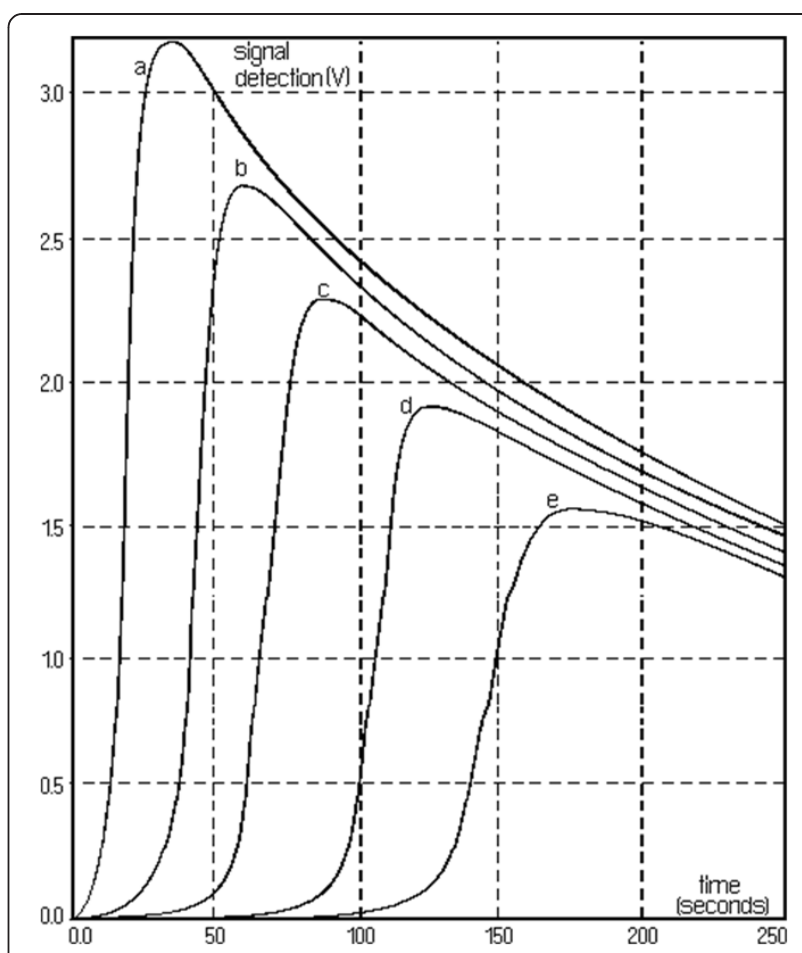

Figure 3 Curves a-e corresponding to increasing antioxidant quantities. 


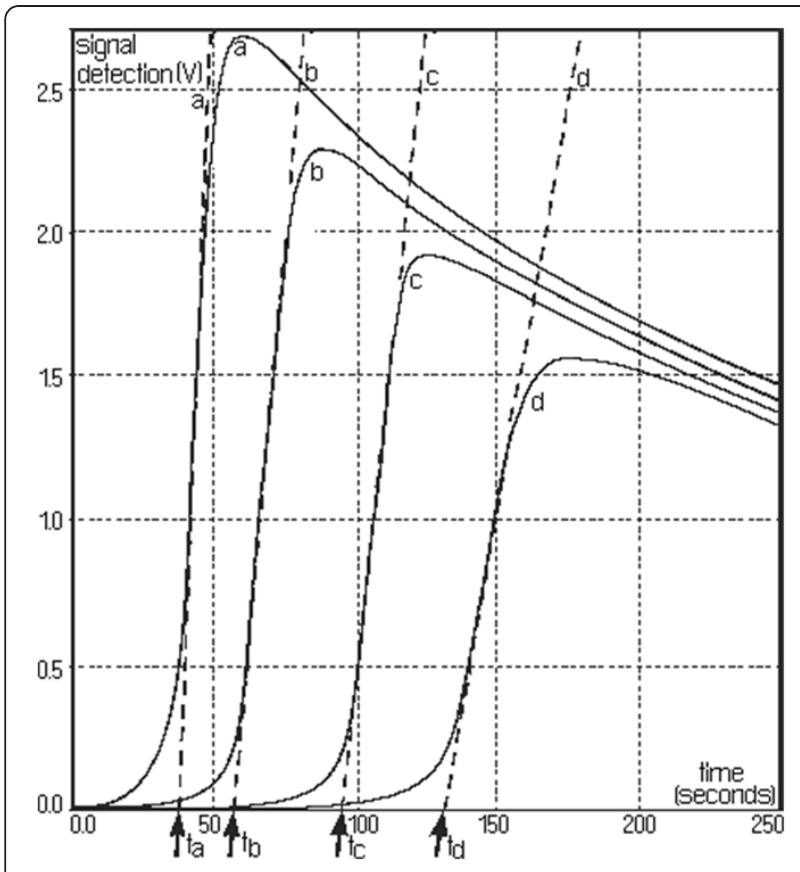

Figure 4 The algorithm for determining induction times.

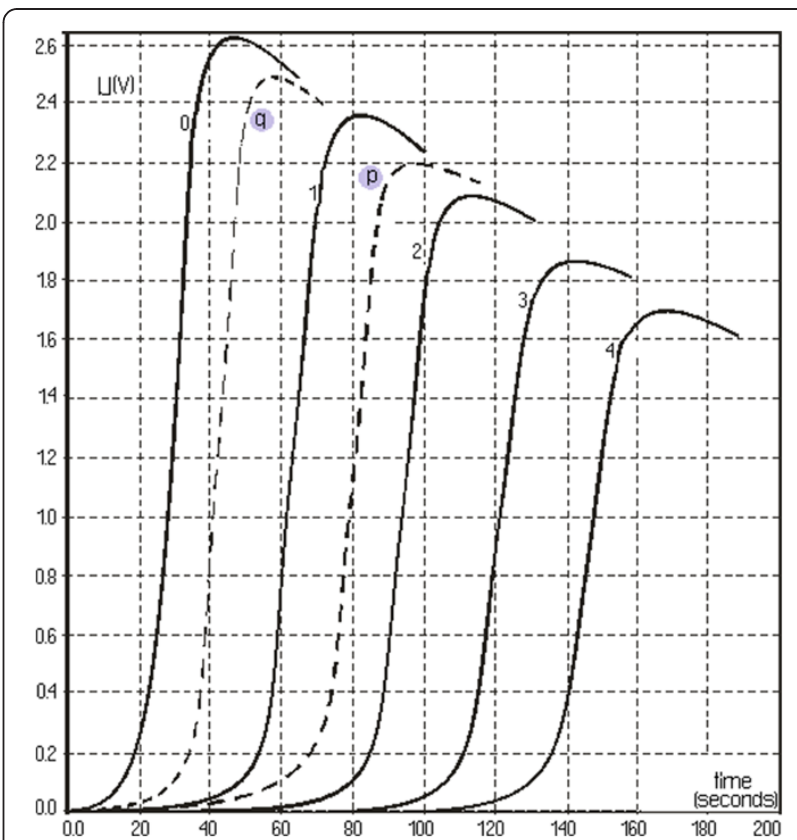

Figure 5 Curves $p$ and $q$ corresponding to fresh and $24 \mathrm{~h}$ at room temperature $A$. ursinum extracts, respectively. samples with those obtained with the help of standard solutions. Following the described studies, it has been observed that the watery extract of $A$. ursinum changes its properties in time. Despite the fact that this change, is not very visible in the UV absorption spectrum (Figure 1), it becomes evident in the study on the antioxidant capacity. The induction time corresponds to the intersection between the time axis and the tangent to the respective curve, at its inflection point.

The curves $\mathrm{p}$ and $\mathrm{q}$ in Figure 5 correspond to fresh and 24 hours at room temperature $A$. ursinum extracts, respectively. They correspond to the first and last lines in Table 2, respectively. Intermediate samples, included in Table 2, generate luminiscence curves between those labelled with $\mathrm{p}$ and $\mathrm{q}$ in Figure 5. Data on the series of standard solutions, included in Table 1, acceptably confirm a linear relationship (Figure 6).

Table 2 and Figure 7 present in figures and graphs, respectively, the decrease in time of the antioxidant activity. The decrease in the antioxidant activity confirms

Table 1 Values of induction times (IT) and effective induction times (EIT)

\begin{tabular}{lll}
\hline TI (s) & TIE (s) & nmol vitamin C \\
\hline 22.9 & 0.0 & 0.0 \\
55.8 & 32.9 & 0.5 \\
85.4 & 62.5 & 1.0 \\
112.1 & 89.2 & 1.5 \\
136.3 & 113.4 & 2.0 \\
\hline
\end{tabular}

an exponential relation which formally may be associated to a kinetically pseudo-monomolecular process. The exponential regression equation allows the half-time of the degradation process to be determined, this being of 14 hours and 49 minutes in a watery environment at room temperature.

\section{Discussion}

Using the literature value of the specific absorbance at $240 \mathrm{~nm}(145.4 \mathrm{dL} / \mathrm{g} \cdot \mathrm{cm})$, the allicin content reported to the used raw material could be determined i.e. $0.694 \mu \mathrm{g} / \mathrm{ml}$.

The determination of the antioxidant capacity is based upon photochemical generation initiated by an UV radiation in the $185-240 \mathrm{~nm}$ domains, of the anion $\left(\mathrm{O}^{-}{ }_{2}^{\circ}\right)$ superoxide radical. The sequence presented in Schemes 1

Table 2 Decrease in time of the antioxidant activity of the $A$. ursinum watery extract

\begin{tabular}{lll}
\hline Time of degradation (ore) & TIE (s) & Nmol vitamin C \\
\hline 0 & 45.4 & 0.75 \\
3 & 39.2 & 0.64 \\
6 & 34.0 & 0.55 \\
9 & 29.1 & 0.46 \\
12 & 25.6 & 0.40 \\
15 & 22.5 & 0.35 \\
18 & 19.7 & 0.30 \\
21 & 17.0 & 0.25 \\
24 & 14.5 & 0.21 \\
\hline
\end{tabular}




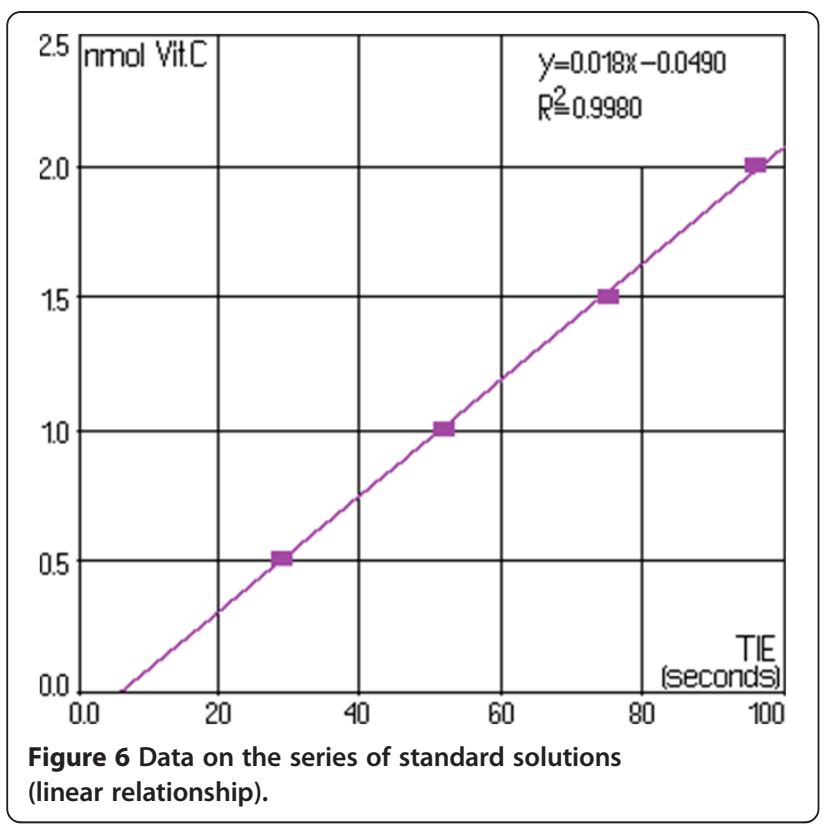

and 2 includes the optical excitation of the free radical generator (damnacantal) thus obtaining the singlet state (1 s) of the molecule (process [A]). By an "inter system crossing"-type process (process [B]), the molecule goes into the triplet state which, due to known molecular spectroscopy selection rules, is stable enough to react either with oxygen in the normal triplet state (generating the singlet oxygen reactive species) (process [C]), or with a reducing (also called a reductant or reducer) agent (mono-electronic reduction process) (process [D]) with the generation of an anion radical in doublet state $\left({ }^{2} S\right)$ and the formation of the superoxide anion (process $[E]$ ).

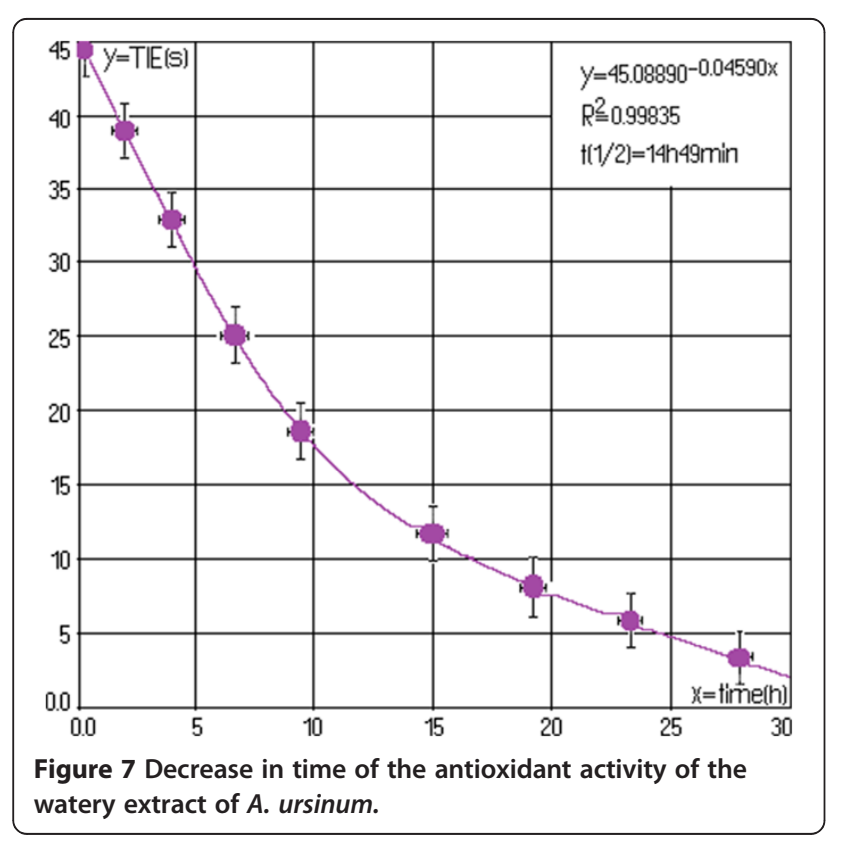

The latter, by a series of processes $([\mathrm{A}]-[\mathrm{H}])$, transforms into the amino orthophthalic acid dianion, in the singlet state, which, by reversal process to the fundamental state, emits a light beam in the $425-450 \mathrm{~nm}$ spectral domain [22]. Antioxidants from the captured samples yield superoxide ions and reduce the radiation intensity generated by excited luminol (luminol reaction inhibiting-blank). Standard soluble compounds are TROLOX (derivate of $\alpha$-tocopherol), and for the water-soluble, ascorbic acid.

For both it performs a calibration curve and estimate the advance between the integral under the curve of the blank (solution without antioxidant) and sample (standard solution or extract with antioxidant-plant) and distribute by the standard integral.

These estimates are done automatically by the software unit.

The intensity of the light signal, measured by a photomultiplier, depends on the speed of the processes $[\mathrm{F}]$ and [G]. If the system does not include a compound capable to bond free radicals, the entire amount of generated anion superoxide is consumed by the light supplying agent "luminol", and the intensity of the emitted light is maximal.

If the system contains an amount of free radical binding agents (antioxinants) a competition between luminol and the free radical binding agents occurs for the superoxide anion radical. In this case the light signal detected by the photomultiplier has a lower intensity [23]. The unimolecular decomposition of methyl methane thiosulfate is favoured by the weak $\mathrm{S}-\mathrm{S}$ bond which has the energy of $46+/-4.6 \mathrm{kcal} / \mathrm{mol}$ comparable to the energy for the dissociation of the $\mathrm{S}-\mathrm{S}$ bond in dimethyl trisulfure but considerably lower than in dimethyl disulfide (75 kcal/mol) [24].

By comparison, the $\mathrm{S}-\mathrm{S}$ bonding energies in phenyl benzene tiosulfinate and diphenyl disulfur are 35 and $65 \mathrm{kcal} / \mathrm{mol}$, respectively. The oxygen in tiosulfinate participates in the hydrogen bond, even if not as strong as the oxygen in sulfoxydes [25]. By using the strength of the hydrogen bond, metan tiosulfinate, ethylethane thiosulfinate and dimetyl sulfoxide were demonstrated to cause 278, 308 and $360 \mathrm{~cm}^{-1}$ changes, respectively, in the vibration frequency of the bond. In order to answer the question on the way to benefit from an Alliaceae diet, the following recommendations may be formulated: The texture of Alliaceae species is completely crushed when these are consumed, thus allowing a large amount of S-oxyde S-alkenylcysteine to enter unchanged into the intestinal tract. As alliinase are ireversibly inactivated by the gastric $\mathrm{pH}$, sulfoxides are cleaved by intestinal bacteria into corresponding disulfures [26]. Thiosulfinates which reach the stomach survive the low $\mathrm{pH}$ long enough to attack existing pathogenic microorganisms. The allk(en)yltiolation of certain SH biological groups by 


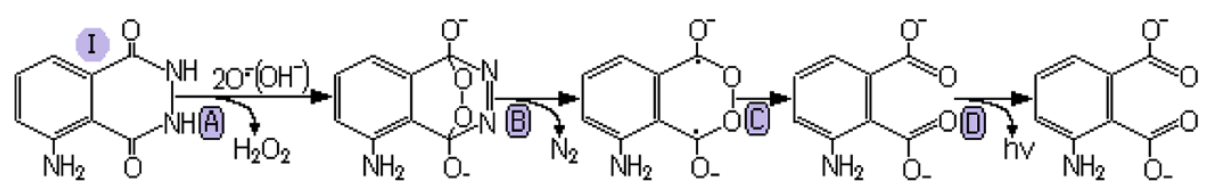

Scheme 1 Process [A]-obtaining the singlet state $(1 \mathrm{~s})$ of the molecule; process [B]-process the molecule goes into the triplet; process $[C]$-generating the singlet oxygen reactive species; process [D]-the generation of an anion radical in doublet state $\left({ }^{2} \mathrm{~S}\right)$.

thiosulfinates, di- or polysulfures or ajoene is beneficial (tiamine allyl tiolation occurs rapidly with the generation of allyl tiamine which is easier absorbed from the intestine than tiamine). The disulfures and other sulfur compounds formed in Alliaceae species play a role in the intestinal tract by deactivation of nitrites or other environmental toxins [27]. The metabolic pathway of Alliaceae organosulfur compounds represents an important field for future research.

\section{Conclusions}

The study confirms the literature statement that the $A$. ursinum watery extract has an antioxidant capacity lasting for several hours. The half-time, as experimentally determined in this study, is 15 hours and 45 minutes at room temperature.

As such, after 24 hours, the antioxidant capacity of an A. ursinum watery extract is decreased. Observing the degradation process in time, an exponential relation was described which may formally correspond to a kinetically pseudomonomolecular model. Even if absorbance reported to specific wavelengths correspond to the domain indicated in literature for the allicin component, the lack of a well-defined chromophore in the allicin molecule does not allow an effective monitoring of the degradation process. Unlike the UV study, monitoring the antioxidant capacity by chemiluminescence method represents a rapid, comfortable and adequate technique for monitoring allicin changes in a watery environment.

\section{Methods}

\section{Equipments and substances}

UV absorption spectra were recorded with a PG Instruments UV-VIS spectrophotometer using the UV WIN 5.05 software. The antioxidant capacity was determined by chemiluminiscence using the "PHOTOCHEM" dedicated device produced by Jena Analytic, Germany. The standard substances were purchased from Sigma Aldrich.

\section{Obtaining the extract}

A fresh ramson bulb was collected from April to May in deciduous forests (western part of Romania) weighed with the semi micro analytical scale $(7.00 \mathrm{~g})$ is crushed in a grinding mortar and homogenized in $50 \mathrm{~mL}$ distilled water. The homogenized matter is quantitatively transformed in a $250 \mathrm{~mL}$ measuring bottle and the volume is completed with distilled water. The nonhomogeneous content of the bottle is filtered during several stages, using filtration membranes with increasingly lower porosity (osmonics-type membranes, manufactured by Micron Separations Inc.).

\section{The spectrophotometric study of the extract}

The filtrate is diluted 30 times with distilled water to obtain the working solution. The UV absorption spectrum of the working solution was obtained against distilled water in a $1 \mathrm{~cm}$ quartz cuvette. In order to argument the identity of the absorbing species (allicin), the absorbance report measured at 240-254 $\mathrm{nm}$ is determined according to literature specifications. For the fresh watery extract, this report is 1.442 , value situated in the 1.4-1.5 interval also indicated by literature data [25].

\section{Determination and characterization of the antioxidative capacity}

Eight $2 \mathrm{~mL}$ aliquots from the working solution are frozen at $-10^{\circ} \mathrm{C}$. By successively defreezing these aliquots, the antioxidant capacity is measured every 3 hours. The determination of antioxidant capacity is based upon the photochemical generation of the superoxide anion radical initiated by a $185-240 \mathrm{~nm}$ UV beam.

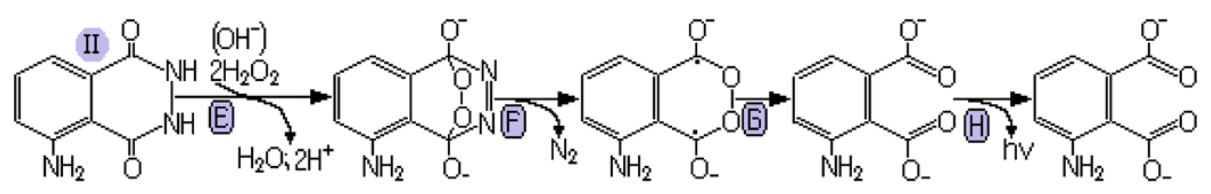

Scheme 2 Process [E], [F] and [G]- the formation of the superoxide anion; processes [H]- transforms into the acid dianion. 


\section{Competing interests}

The authors declare that they have no competing interests.

\section{Authors' contributions}

$\mathrm{MB}$ conceived the study, participated in the design and co-ordination of the experiments and data interpretation and helped draft the manuscript. AC and SP produced samples, performed data analysis and data interpretation. All authors have equal rights and all authors read and approved the final manuscript.

\section{Acknowledgements}

The authors thank Prof. Zoltan Szabadai, MD, PhD. for helpful discussions and critical reading of the manuscript.

\section{Author details}

${ }^{1}$ Faculty of Medicine, Department of Hygiene, "Victor Babes" University of Medicine and Pharmacy, Bd. Victor Babes, no. 16, 300226, Timisoara, Romania. ${ }^{2}$ Faculty of Pharmacy, "Victor Babes" University of Medicine and Pharmacy, 2A Eftimie Murgu Square, Timisoara 300041, Romania. ${ }^{3}$ Chemistry and Vegetal Biochemistry, Banat's University of Agricultural Sciences and Veterinary Medicine from Timisoara, Calea Aradului no. 119, 300645, Timisoara, Romania.

Received: 20 December 2012 Accepted: 29 January 2013 Published: 1 February 2013

\section{References}

1. Bagheri F, Gol A, Dabiri S, Javadi A: Preventive effect of garlic juice on renal reperfusion injury. Iran J Kidney Dis 2011, 5:194-200.

2. Ray $B$, Chauhan NB, Lahiri DK: Oxidative insults to neurons and synapse are prevented by aged garlic extract and S-allyl-L-cysteine treatment in the neuronal culture and APP-Tg mouse model. J Neurochem 2011, 117:388-402.

3. Bagiu RV, Vlaicu B, Butnariu M: Chemical composition and in vitro antifungal activity screening of the allium ursinum L. (Liliaceae). Int J Mol Sci 2012, 13:1426-1436.

4. Stajner D, Popović BM, Canadanović-Brunet J, Stajner M: Antioxidant and scavenger activities of Allium ursinum. Fitoterapia 2008, 79:303-305.

5. Sapunjieva T, Alexieva I, Mihaylova D, Popova A: Antimicrobial and antioxidant activity of extracts of Allium ursinum L. J BioSci Biotech 2012, $143-145$.

6. Touloupakis E, Ghanotakis DF: Nutraceutical use of garlic sulfur-containing compounds. Adv Exp Med Biol 2010, 698:110-121.

7. Iciek M, Kwiecień I, Włodek L: Biological properties of garlic and garlicderived organosulfur compounds. Environ Mol Mutagen 2009, 50:247-265.

8. Wabwoba BW, Anjili CO, Ngeiywa MM, Ngure PK, Kigondu EM, Ingonga J, Makwali J: Experimental chemotherapy with Allium sativum (Liliaceae) methanolic extract in rodents infected with Leishmania major and Leishmania donovani. J Vector Borne Dis 2010, 47:160-167.

9. Kubec R, Krejcová P, Simek P, Václavík L, Hajslová J, Schraml J: Precursors and formation of pyrithione and other pyridyl-containing sulfur compounds in drumstick onion. Allium stipitatum. J Agric Food Chem 2011, 59:5763-5770.

10. Block $\mathrm{E}$ : The organosulfur chemistry of the genus allium-implications for the organic chemistry of sulfur. Angew. Chem Int Ed Engl 1992, 31:1135-1178.

11. Robène-Soustrade I, Legrand D, Gagnevin L, Chiroleu F, Laurent A, Pruvost O: Multiplex nested PCR for detection of Xanthomonas axonopodis pv. allii from onion seeds. Appl Environ Microbiol 2010, 76:2697-2703.

12. Musah RA, He Q, Kubec R: Discovery and characterization of a novel lachrymatory factor synthase in Petiveria alliacea and its influence on alliinase-mediated formation of biologically active organosulfur compounds. Plant Physiol 2009, 151:1294-1303.

13. Sengupta A, Ghosh S, Bhattacharjee S: Allium vegetables in cancer prevention: an overview. Asian Pac J Cancer Prev 2004, 5:237-245.

14. Young-Jik K: Effects of dietary supplementation of garlic by-products on total phenol contents, DPPH radical scavenging activity, and physicochemical properties of chicken meat. Korean J Food Sci Anim Resour 2010, 30:860-866.

15. Jung-Hye S, Duck-Joo C, Soo-Jung L, Ji-Young C, Jeong-Gyun K, Nak-Ju S: Changes of physicochemical components and antioxidant activity of garlic during its processing. J Life Sci 2008, 18:1123-1131.
16. O'Donnell G, Poeschl R, Zimhony O, Gunaratnam M, Moreira JB, Neidle S, Evangelopoulos D, Bhakta S, Malkinson JP, Boshoff HI, Lenaerts A, Gibbons $\mathrm{S}$ : Bioactive pyridine-N-oxide disulfides from Allium stipitatum. J Nat Prod 2009, 72:360-365.

17. Kang MH, Park HM: Hypertension after ingestion of baked garlic (Allium sativum) in a dog. J Vet Med Sci 2010, 72:515-518.

18. Nasim SA, Dhir B, Samar F, Rashmi K, Mahmooduzzafa Mujib A: Sulphur treatment alters the therapeutic potency of alliin obtained from garlic leaf extract. Food Chem Toxicol 2009, 47:888-892.

19. Jong-Kwan J, Se-Young Y, Jin-Su K, Young-Woo K, Ku Y, Il-Kyung K, Byung-Jo C: Effect of garlic extract supplementation on growth performance, nutrient digestibility, carcass characteristics and meat composition in broilers. Korean J Poultry Sci 2009, 36:287-292.

20. Picard $Y$, Roumagnac $P$, Legrand D, Humeau L, Robène-Soustrade I, Chiroleu F, Gagnevin L, Pruvost O: Polyphasic characterization of Xanthomonas axonopodis allii associated with outbreaks of bacterial blight on three Allium species in the Mascarene archipelago. Phytopathology 2008, 98:919-925.

21. Ryzhikov MA, Ryzhikova VO: Application of chemiluminescent methods for analysis of the antioxidant activity of herbal extracts. Vopr Pitan 2006, 75:22-26.

22. Modelli A, Jones D: Temporary anion states and dissociative electron attachment in diphenyl disulfide. J Phys Chem A 2006, 110:10219-10224.

23. Beato MV, Sánchez HA, de Castro A, Montaño A: Effect of processing and storage time on the contents of organosulfur compounds in pickled blanched garlic. J Agric Food Chem 2012, 60:3485-3491.

24. Yamaji M, Tojo S, Takehira K, Tobita S, Fujitsuka M, Majima T: S-S bond mesolysis in alpha, alpha'-dinaphthyl disulfide radical anion generated during gamma-radiolysis and pulse radiolysis in organic solution. J Phys Chem A 2006, 110:13487-13491.

25. Singh V, Belloir C, Siess MH, Le Bon AM: Inhibition of carcinogen-induced DNA damage in rat liver and colon by garlic powders with varying alliin content. Nutr Cancer 2006, 55:178-184.

26. Antonello S, Daasbjerg K, Jensen H, Taddei F, Maran F: Formation and cleavage of aromatic disulfide radical anions. J Am Chem Soc 2003, 125:14905-14916.

27. Rybak ME, Calvey EM, Harnly JM: Quantitative determination of allicin in garlic: supercritical fluid extraction and standard addition of alliin. J Agric Food Chem 2004, 52:682-687.

doi:10.1186/1752-153X-7-21

Cite this article as: Putnoky et al: Study on the stability and antioxidant effect of the Allium ursinum watery extract. Chemistry Central Journal 2013 $7: 21$.

\section{Publish with ChemistryCentral and every scientist can read your work free of charge \\ “Open access provides opportunities to our colleagues in other parts of the globe, by allowing anyone to view the content free of charge." W. Jeffery Hurst, The Hershey Company.}

- available free of charge to the entire scientific community

- peer reviewed and published immediately upon acceptance

- cited in PubMed and archived on PubMed Central

- yours - you keep the copyright

Submit your manuscript here:

http://www.chemistrycentral.com/manuscript/
()

ChemistryCentral 